\begin{tabular}{||l|l||}
\hline \begin{tabular}{|l} 
Additional \\
Information
\end{tabular} & $\begin{array}{l}\text { NOTICE: This is the author's version of a work that was accepted for } \\
\text { publication in Journal of Chromatography A. Changes resulting from the } \\
\text { publishing process, such as peer review, editing, corrections, structural } \\
\text { formatting, and other quality control mechanisms may not be reflected in } \\
\text { this document. Changes may have been made to this work since it was } \\
\text { submitted for publication. A definitive version was subsequently } \\
\text { published in Journal of Chromatography A. Vol. 1241, 8 June, 2012. DOI: } \\
\text { http://dx.doi.org/10.1016/j.chroma.2012.04.037 }\end{array}$ \\
\hline \hline \begin{tabular}{l|l} 
Alternative \\
Location
\end{tabular} & http://dx.doi.org/10.1016/j.chroma.2012.04.037 \\
\hline
\end{tabular}




\section{Determination of halonitromethanes and haloacetamides: an evaluation of sample preservation and analyte stability in drinking water}

Authors: Deborah Liew, Kathryn L. Linge*, Cynthia A. Joll, Anna Heitz, and Jeffrey W. A. Charrois

Curtin Water Quality Research Centre, Department of Chemistry, Curtin University, GPO Box U1987 Perth, Western Australia 6845, Australia

Correspondence to: Dr. K. Linge, Curtin Water Quality Research Centre, Department of Chemistry, Curtin University, GPO Box U1987 Perth, Western Australia 6845, Australia.

E-mail: k.linge@curtin.edu.au

Phone: +61 892667534

Fax: +61892662300

Keywords: disinfection by-products, halonitromethanes, haloacetamides, GC-MS, nitrogenous disinfection by-products

\section{Abstract}

Simultaneous quantitation of 6 halonitromethanes (HNMs) and 5 haloacetamides (HAAms) was achieved with a simplified liquid-liquid extraction (LLE) method, followed by gas chromatography-mass spectrometry. Stability tests showed that brominated tri-HNMs immediately degraded in the presence of ascorbic acid, sodium sulphite and sodium borohydride, and also reduced in samples treated with ammonium chloride, or with no preservation. Both ammonium chloride and ascorbic acid were suitable for the preservation of HAAms. Ammonium chloride was most suitable for preserving both HNMs and HAAms, although it is recommended that samples be analysed as soon as possible after collection. While groundwater samples exhibited a greater analytical bias compared to other waters, the good recoveries $(>90 \%)$ of most analytes in tap water suggest that the method is very appropriate for determining these analytes in treated drinking waters. Application of the method to water from three drinking water treatment plants in Western Australia indicating N-DBP formation did occur, with 
increased detections after chlorination. The method is recommended for low-cost, rapid screening of both HNMs and HAAms in drinking water.

\section{Introduction}

Nitrogenous disinfection by-products (N-DBPs) are a group of organic by-products that can be formed during the disinfection of water sources rich in organic nitrogen [1,2]. Halonitromethanes (HNMs) and haloacetamides (HAAms) are 2 classes of N-DBPs that are unregulated, but raise questions for public heath protection because they are more toxic than the regulated disinfection byproducts (DBPs) [3-5]. The HNMs have been identified as extremely cytotoxic and genotoxic [4], with the brominated HNMs ranked among the DBPs with the highest potential toxicities $[5,6]$. Haloacetamides have also been found to be more genotoxic and cytotoxic than currently regulated haloacetic acids [3]. Nine bromine- and chlorine-substituted HNMs, and five bromine- and chlorine-substituted HAAms have been identified in drinking waters to date [6-9], however neither class has been comprehensively studied.

A lack of routine or well-validated analytical methods to measure these N-DBPs is one factor that is hindering studies of the formation and occurrence of HNMs and HAAms in drinking waters . Analytical methods for HNMs and HAAms have recently been reviewed [1,10]. Reported methods generally employ a liquid-liquid extraction (LLE) procedure based on the USEPA method 551.1 [11], with or without modification, followed by gas chromatography with electron-capture detection (GC-ECD) [9,12,13] and/or gas chromatography with mass spectrometry (GC-MS) [3,14,15]. determination of nine HNMs in tap and swimming pool water [16,17], which are more sensitive than LLE but also require specialized headspace sampling equipment. Sample preservation is also critical for maintaining sample integrity in finished drinking water samples where a disinfectant residual may exist. However, it is equally important that the added preservative does not affect analyte concentrations during sample storage. Various preservatives have been recommended [18], including sodium sulphite, ammonium chloride and ascorbic acid. Some studies, however, have demonstrated that these preservatives can interact with certain DBPs, altering apparent concentrations $[9,19,20]$. In particular, HNMs are known to undergo rapid degradation when exposed to certain preservatives $[9,12,20]$.

Here we report the validation of a single analytical method developed for the quantitation of 6 HNMs and 5 HAAms in drinking water samples, using LLE followed by GC-MS. Extraction by LLE was employed because of its demonstrated suitability for both HNMs and HAAms. To our knowledge, this is the first report of an analytical method for the simultaneous determination of both HNMs and HAAms. In addition, the effect of four commonly used preservatives, ammonium 
chloride, ascorbic acid, sodium sulphite and sodium borohydride, were evaluated for their suitability in the determination of both HNMs and HAAms. Finally, the proposed method was used to characterize HNMs and HAAms in selected drinking water treatment plants in Western Australia.

\section{Experimental}

\subsection{Reagents and standards}

Trichloronitromethane (TCNM, chloropicrin, $5000 \mu \mathrm{g} / \mathrm{mL}$ in acetone) was obtained from AccuStandard Inc. (New Haven, USA). All other target analytes were purchased as neat compounds with purities between 85 and 99.5\%; bromochloronitromethane (BCNM), dichloronitromethane (DCNM) bromodichloronitromethane (BDCNM), dibromochloronitromethane (DBCNM), tribromonitromethane (TBNM, bromopicrin,) and dibromoacetamide (DBAAm) from Orchid Cellmark (New Westminister, Canada), bromoacetamide (BAAm), dichloroacetamide (DCAAm) and trichloroacetamide (TCAAm) from Sigma-Aldrich (Castle Hill, Australia), and chloroacetamide (CAAm) from ChemService (Westchester, USA). Deuterated compounds, [ $\left.{ }^{2} \mathrm{H} 6\right]$ 1,2-dibromopropane (1,2-dibromopropane- $\left.\mathrm{d}_{6}, 99.7 \%\right)$ and $\left[{ }^{2} \mathrm{H} 2\right]$ 1,1,2,2-tetrachloroethane $(1,1,2,2-$ tetrachloroethane- $\mathrm{d}_{2}, 99.5 \%$ ), were from CDN Isotopes (Pointe-Claire, Canada) and Sigma Aldrich (Castle Hill, Australia), respectively. Stock solutions $\left(1 \mathrm{mg} / \mathrm{mL}\right.$ in acetone) were stored at $-14^{\circ} \mathrm{C}$.

Acetone ( $>99.5 \%$, HPLC grade) was from Mallinckrodt Baker (Phillipsburg, USA) and methyl-tertbutyl-ether (MTBE) ( $>99 \%$, ACS reagent) was from Sigma-Aldrich (Castle Hill, Australia). Sodium sulphate, magnesium sulphate and hydrochloric acid (analytical grade or better) were from Ajax Finechem (Taren Point, Australia). Reagents used in preservation and stability studies included ammonium chloride (99.5\%, Biolab (Aust) Clayton, Australia), L-Ascorbic acid ( $>99 \%$, Sigma-Aldrich, Castle Hill, Australia), sodium sulfite and sodium borohydride (98\% and 97\%, respectively, Ajax Finechem, Taren Point, Australia).

\subsection{Analysis of HNMs and HAAms}

The LLE method employed was adapted from USEPA Method 551.1 [11], and optimised for solvent extraction volume, extraction $\mathrm{pH}$ and salt addition. Full details of the LLE optimisation and final procedure are provided in the Supporting Information (SI).

GC-MS determination was undertaken using an Agilent-6890N Gas Chromatograph coupled with a 5975 mass selective detector (MSD), operating in the electron impact ionization (EI) mode. Chromatographic peaks for target analytes were identified based on retention time and the presence of qualifying ions (SI Table S1). Generally the ion that had the highest intensity was chosen as the quantifying ion. The HAAms exhibit characteristic "tailing" peak shapes, which have been attributed to interactions with the EI ion source [3], which aided in peak identification. 


\subsection{Sample preservation and analyte stability}

100 Ultrapure water and tap water samples were fortified with 10 or $20 \mu \mathrm{g} / \mathrm{L}$ of the target N-DBPs.

101 Preservation agents (ascorbic acid, $20 \mathrm{mg} / \mathrm{L}$; ammonium chloride, $100 \mathrm{mg} / \mathrm{L}$; sodium borohydride,

$10240 \mathrm{mg} / \mathrm{L}$; sodium sulphite, $25 \mathrm{mg} / \mathrm{L}$ ) were added in excess to simulate quenching a residual of at

103 least $5 \mathrm{mg} / \mathrm{L}$ free chlorine. Preliminary tests using ultrapure water tested the immediate effects of

104 each preservative on target N-DBPs. Following these, ammonium chloride and ascorbic acid were

105 selected for further study over 14 days. The effect of $\mathrm{pH}$ (4-8) was also evaluated using unpreserved

106 ultrapure water samples adjusted with dilute hydrochloric acid or sodium hydroxide. Samples were stored in the dark at $4^{\circ} \mathrm{C}$ during each test, and analysed at $1,2,3,4,7,10$ and 14 days.

\subsection{Sample collection}

Raw and treated drinking waters were sampled from selected water treatment plants in Western Australia between June 2010 and December 2010. Sample sites included two groundwater treatment plants in metropolitan Perth and one surface water treatment plant in the northwest of Western Australia, all utilising conventional treatment and chlorine disinfection. Raw source water ranged in dissolved organic carbon $(3-12 \mathrm{mg} / \mathrm{L})$ and total nitrogen content $(0.2-0.7 \mathrm{mg} / \mathrm{L})$, and treatment processes varied. Each site was sampled for raw water, treated water (post-disinfection) and distribution system water (reticulation). Sampling procedures are detailed in the SI.

\section{Results \& Discussion}

\subsection{Analyte stability}

\subsubsection{Sample preservation}

Preliminary analyte degradation tests using spiked $(20 \mu \mathrm{g} / \mathrm{L})$ ultrapure water treated with ammonium chloride (100 mg/L), ascorbic acid (20 mg/L), sodium sulphite $(25 \mathrm{mg} / \mathrm{L})$ or sodium borohydride $(40 \mathrm{mg} / \mathrm{L})$ demonstrated that the response ratios (equal to the ratio of the peak area of the analyte to the peak area of the surrogate standard, 1,2-dibromopropane- $\mathrm{d}_{6}$ ) of the brominated triHNMs (BDCNM, DBCNM and TBNM) all decreased in the presence of ascorbic acid, sodium sulphite and sodium borohydride, compared to samples with no preservation (SI Figure S1). Only ammonium chloride treatment resulted in brominated tri-HNMs response ratios comparable to those in unpreserved samples. Sodium sulphite and sodium borohydride also produced a decrease in the response ratio for TCNM. Response ratios for some HAAm increased in the presence of ascorbic acid, although this was not investigated further. The decrease in HNM concetrations observed in the presence of sodium borohydride and sodium sulphite is attributed their strong reducing nature and longer-term (14-day) stability tests were undertaken with ascorbic acid and ammonium chloride only. 


\subsubsection{4-day stability study}

133 The effect of either ascorbic acid or ammonium chloride were tested over 14 days using spiked (20

$134 \mu \mathrm{g} / \mathrm{L})$ ultrapure water (Figure 1), and spiked (20 $\mu \mathrm{g} / \mathrm{L})$ tap water samples, with and without chlorine addition after preservation (Figure 2). Results of BAAm and CAAm are not shown due to their poor response in early studies, which meant that these analytes could not be conclusively determined throughout the stability test period. In ultrapure water the stabilities of DBAAm, DCAAm, TCAAm, TCNM, BCNM and DCNM were comparable for three preservation scenarios (i.e., no preservation, ascorbic acid, and ammonium chloride). However, the brominated tri-HNMs were never detected in ascorbic acid treated samples, and rapidly decreased within the first 3 days for samples with no preservation, or when treated with ammonium chloride (Figure 1). The results confirmed that treatment with ascorbic acid quickly degraded the brominated tri-HNMs, but did not affect other analytes. The findings were similar in tap water without chlorine addition (Figure 2), however the degradation of HNM species in unpreserved and ammonium chloride-quenched samples was noticeably greater for tap water than for ultrapure water. There were no clear indications of instability of HAAms during the period of testing, regardless of water type or preservative, although there were slight fluctuations in the responses of these analytes.

148 High concentrations of chlorine resulted in the rapid destruction of HAAms, presumably due to their conversion to haloacetic acids in the presence of free chlorine [8]. The concentrations of some HAAms (DCAAm, TCAAm and DBAAm) decreased immediately upon the addition of further chlorine $(3 \mathrm{mg} / \mathrm{L})$ to (already chlorinated) tap water without preservation or when treated with ammonium chloride (Figure 2). Treatment with ascorbic acid preserved the concentrations of these HAAms in chlorinated tap water. While treatment with ammonium chloride did not preserve HAAm concentrations, no further degradation was detected after the initial chlorination, and levels of HAAms were similar to that in unpreserved chlorinated tap water. Thus the use of ammonium chloride as a preservative for HAAms is still applicable to chlorinated samples.

Interestingly, the initial responses of the brominated tri-HNMs were significantly higher when tap water was treated with $3 \mathrm{mg} / \mathrm{L}$ free chlorine after preservation, for both unpreserved and ammonium chloride-quenched samples. All 3 brominated tri-HNMs behaved similarly and responses for TCNM were also notably higher in tap water with $3 \mathrm{mg} / \mathrm{L}$ free chorine. Furthermore, TCNM increased in the unpreserved chlorinated tap water after day 4, suggesting there was additional formation of TCNM in the water in the presence of free chlorine. TCNM is formed during chlorination $[21,22]$, but there is little information in the literature to determine whether significant levels of HNMs are expected to form at the free chlorine concentration added in our experiments. 
165 Overall, it is clear that many HNMs are unstable and serve as the limiting factor in the application 166 of this method for the analysis of HNMs and HAAms. Therefore, it is recommended that samples be kept at $4^{\circ} \mathrm{C}$ and analysed as soon as possible upon laboratory receipt, to minimize loss of analytes. Ammonium chloride has previously been recommended over ascorbic acid for the preservation of brominated HNMs [9] and results from this study confirm that ammonium chloride is the most suitable preservation agent for both HNMs and HAAms over short periods of time. However, it is important to note that the dechlorinating mechanism of ammonium chloride involves the conversion of free chlorine to combined chlorine (i.e. monochloramine) [11]; therefore, it does not act as a quenching agent in chloraminated samples. A more effective quenching agent for chloramination that does not affect HNMs and HAAms has yet to be proposed. In these cases, we recommend samples remain unpreserved but analysed as soon as possible.

\subsubsection{The effect of $p H$}

HNMs and HAAms are generally susceptible to base-catalysed degradation [14,23], however DCAAm is also known to undergo hydrolysis under strongly acidic conditions [23]. The influence of $\mathrm{pH}$ on the stability of target analytes was studied in ultrapure water containing $20 \mu \mathrm{g} / \mathrm{L}$ of target analytes at pHs 4, 5, 6, 7 and 8, over 14 days (SI Figure S2). No significant differences were observed in samples between $\mathrm{pH}$ 4-7. However, all three brominated tri-HNMs decreased at a significantly faster rate at $\mathrm{pH} 8$, and reduced to below detection by day 2 . This faster degradation is attributed to base-catalysed hydrolysis occurring at alkaline $\mathrm{pH}$. Overall, these results emphasize that samples should be analysed as soon as possible and should not be stored under alkaline $\mathrm{pH}$ conditions. The use of ammonium chloride as a preservative is advantageous in this respect as it is likely to reduce the $\mathrm{pH}$ of the sample to below $\mathrm{pH} 7$, due to its acidic nature.

\subsection{Method validation}

Table 1 lists calibration and validation data for the analytical method. Method detection limits (MDLs) were calculated according to the USEPA method [24], using the 95\% confidence level of the standard deviation of nine replicate measurements of a low concentration standard. MDLs ranged from $0.08 \mu \mathrm{g} / \mathrm{L}$ for TCNM and DCAAm, to $6 \mu \mathrm{g} / \mathrm{L}$ for TBNM. These are comparable with previously reported limits (i.e. $<1 \mu \mathrm{g} / \mathrm{L}$ ) $[9,16]$ for most of these analytes, other than the brominated tri-HNMs (BDCNM, DBCNM, TBNM) and mono-HAAms (BAAm, CAAm), which presented the least sensitivity. Most analytes showed linear calibration curves $\left(\mathrm{R}^{2}>0.99\right)$, except for the brominated tri-HNMs as well as the mono-HAAms. For these analytes, linearity was generally better over the high $(1-100 \mu \mathrm{g} / \mathrm{L})$ concentration range than the low $(1-20 \mu \mathrm{g} / \mathrm{L})$, which may be explained by a lack of sensitivity and responses at low concentrations. Bias of the analytical method was evaluated by measuring untreated surface water, groundwater and tap water, each spiked with 
$20 \mu \mathrm{g} / \mathrm{L}$ of analytes (in triplicate). Overall, the good recoveries of analytes other than the

200 brominated tri-HNMs in tap water show that the method is appropriate for determining the presence of these analytes in treated drinking waters. Relative standard uncertainties were calculated for after identifying relevant uncertainty sources via a cause and effect diagram [25]. The uncertainty budget incorporated precision calculated as the relative standard deviation of triplicate spiked samples, calibration standard preparation, sample volume, and linear regression of the calibration curve. Generally the greatest source of uncertainty was precision (precision ranged from 4-31\%), although linear regression of the calibration curve was also a significant source of error, particularly for the brominated tri-HNMs .

\subsection{Analysis of drinking water samples}

209 Concentrations of HNMs and HAAms were quantified in raw and treated drinking waters from two groundwater treatment plants in metropolitan Perth, and one surface water treatment plant in the northwest of Western Australia (Table 2), quantified via external calibration. Field and trip blank sample results were always below detection limits. None of the analytes were detected in any of the raw source waters, but were detected after disinfection with chlorine. The frequency of detections immediately post-chlorination was similar to the frequency of detections in the distribution system and there were no clear trends of either increasing or decreasing concentration with incresing residence time in the distribution system.

Only one HNM (DCNM), and three HAAms (CAAm, DCAAm and DBAAm) were measured at quantifiable concentrations. Dihalogenated species were the most frequently detected. The detected concentrations were similar to previously reported values (low $\mu \mathrm{g} / \mathrm{L})$ of these compounds in drinking waters from North America [9]. Further application of this method will provide an opportunity to prioritise these N-DBPs, potentially leading to further investigation of their toxicity, and understanding of their formation in drinking water sources.

\section{Conclusions}

Stability and validation studies indicate that HNMs are unstable, extremely sensitive to degradation from many common preservatives, and the limiting factor when applying LLE-GC-MS for the combined analysis of HNMs and HAAms. While ammonium chloride was the most suitable for preserving both HNMs and HAAms, it is important to note that ammonium chloride does not act as a quenching agent in chloraminated samples. An alternative quenching agent for waters from chloraminated systems that does not affect HNMs has yet to be proposed. Ascorbic acid is appropriate for chloraminated samples for preserving HAAms only. 
Despite the higher detection limits for the brominated tri-HNMs and the mono-HAAms achieved in this study, compared to previous studies [9,16], this is the first reported method using GC-MS for the simultaneous determination of HNMs and HAAms. Occurrences of HNMs and HAAms in drinking waters are typically in the low $\mu \mathrm{g} / \mathrm{L}$ range, but drinking water guidelines have not yet been established for these N-DBPs. This method, which can simultaneously measure HNM and HAAm, will be very useful for generating drinking water occurrence data, as well as facilitating future work on the formation and control of these N-DBPs.

\section{Acknowledgements}

The authors thank A. Chan, G. Chidlow and J. Tan (Curtin University) for their valuable assistance in N-DBP analysis and method validation. This study is part of ARC Linkage project LP110100548. The authors thank all project partners, especially L. Breckler (Water Corporation of Western Australia) for coordinating and assisting with sample collection.

\section{Figure Captions}

244 Figure 1. Stability of HNMs and HAAms in ultrapure water fortified with $20 \mu \mathrm{g} / \mathrm{L}$ target analytes, containing no preservative $(\bullet), 100 \mathrm{mg} / \mathrm{L}$ ammonium chloride $(\triangle)$ or $20 \mathrm{mg} / \mathrm{L}$ ascorbic acid $(\square)$. See Table 1 for definition of analyte acronyms.

Figure 2. Stability of HNMs and HAAms in tap water fortified with $20 \mu \mathrm{g} / \mathrm{L}$ target analytes, without chlorine addition, containing no preservative $(\bullet), 100 \mathrm{mg} / \mathrm{L}$ ammonium chloride $(\boldsymbol{\Delta})$ or 20 $\mathrm{mg} / \mathrm{L}$ ascorbic acid ( $\mathbf{m}$ ); and in tap water fortified with $20 \mu \mathrm{g} / \mathrm{L}$ target analytes, with chlorine addition $\left(3 \mathrm{mg} / \mathrm{L}\right.$ free $\left.\mathrm{Cl}_{2}\right)$, containing no preservative $(\bigcirc), 100 \mathrm{mg} / \mathrm{L}$ ammonium chloride $(\triangle)$ or 20 $\mathrm{mg} / \mathrm{L}$ ascorbic acid $(\square)$. See Table 1 for definition of analyte acronyms.

\section{References}

[1] D. Liew, K.L. Linge, A. Heitz, C.A. Joll, Nitrogenous DBPs in drinking water: toxicity, regulation, analysis, occurrence and control, in: S. Hrudey, J.W.A. Charrois (Eds), Disinfection By-Products - Relevance to Human Health, IWA Publishing, 2012.

[2] T. Bond, J. Huang, M.R. Templeton, N. Graham, Water Res. 45 (2011) 4341.

[3] M.J. Plewa, M.G. Muellner, S.D. Richardson, F. Fasano, K.M. Buettner, Y.-T. Woo, A.B. McKague, E.D. Wagner, Environ. Sci. Technol. 42 (2008) 955.

[4] M.J. Plewa, E.D. Wagner, P. Jazwierska, S.D. Richardson, P.H. Chen, A.B. McKague, Environ. Sci. Technol. 38 (2004) 62.

[5] Y.T. Woo, D. Lai, J.L. McLain, M.K. Manibusan, V. Dellarco, Environ. Health Perspect. $110(2002) 75$.

[6] S.W. Krasner, H.S. Weinberg, S.D. Richardson, S.J. Pastor, R. Chinn, M.J. Sclimenti, G.D. Onstad, A.D. Thruston, Environ. Sci. Technol. 40 (2006) 7175.

[7] W.E. Coleman, R.D. Lingg, R.G. Melton, F.C. Kopfler, The occurrence of volatile organics in five drinking water supplies using GC/MS, in: L.H. Keith (Ed), Identification and Analysis of Organic Pollutants in Water, Ann Arbor Science, Ann Arbor, 1976, p. 305.

[8] D.A. Reckhow, T.L. Platt, A.L. MacNeill, J.N. McClellan, J. Water Supply Res. Technol. AQUA 50 (2001) 1. 
[9] H.S. Weinberg, S.W. Krasner, S.D. Richardson, A.D. Thruston, Jr, The Occurrence of Disinfection By-Products (DBPs) of Health Concern in Drinking Water: Results of a Nationwide DBP Occurrence Study, USEPA, Athens, 2002.

[10] J.W.A. Charrois, Analysis of Emerging Disinfection By-Products in Drinking Water, in: R.A. Meyers (Ed), Encyclopedia of Analytical Chemistry, John Wiley \& Sons, Chichester, 2011, p. 205.

[11] D.J. Munch, D.P. Hautman, Method 551.1. Determination of Chlorinated Disinfection Byproducts, Chlorinated Solvents, and Halogenated Pesticides/Herbicides in Drinking Water by Liquid/Liquid Extraction and Gas Chromatography with Electron Capture Detection, USEPA, Cincinnati, 1995.

[12] J. Hoigné, H. Bader, Water Res. 22 (1988) 313.

[13] J. Hu, H. Song, J.W. Addison, T. Karanfil, Water Res. 44 (2010) 105.

[14] P.H. Chen, S.D. Richardson, S.W. Krasner, G. Majetich, G.L. Glish, Environ. Sci. Technol. 36 (2002) 3362.

[15] A.D. Nikolaou, T.D. Lekkas, S.K. Golfinopoulos, M.N. Kostopoulou, Talanta 56 (2002) 717.

[16] I. Montesinos, M.J. Cardador, M. Gallego, J. Chromatogr. A 1218 (2011) 2497.

[17] I. Montesinos, M. Gallego, Analytical and Bioanalytical Chemistry 402 (2012) 2315.

[18] L.S. Clesceri, A.E. Greenberg, A.D. Eaton, Standard Methods for the Examination of Water and Wastewater, APHA, AWWA, WEF, Washington, DC., 20th ed., 1998.

[19] Y. Hong, S.B. Liu, J. Am. Water Works Ass. 99 (2007) 57.

[20] J.P. Croue, D.A. Reckhow, Environ. Sci. Technol. 23 (1989) 1412.

[21] J.P. Duguet, Y. Tsutsumi, A. Bruchet, J. Mallevialle, Chloropicrin in potable water: conditions of formation and evolution along various treatment processes, in: R.L. Jolley, R.J. Bull, W.P. Davis, S. Katz, M.H. Roberts, V.A. Jacobs (Eds), Water Chlorination: Chemistry, Environmental Impact and Health Effects, Lewis Publishers, Chelsea, 1985, p. 1201.

[22] H. Thibaud, J. Delaat, N. Merlet, M. Dore, Water Res. 21 (1987) 813.

[23] W.-H. Chu, N.-Y. Gao, Y. Deng, Chin. J. Org. Chem. 29 (2009) 1569.

[24] in Title 40 Code of Federal Regulations, Part 136, Appendix B, Revision 1.11, USEPA, 2005.

[25] S.L.R. Ellison, M. Rosslein, A. Williams, Quantifying Uncertainty in Analytical Measurement, EURACHEM, CITAC, 2000. 
Table 1. Calibration and validation data for the analytical method. Method detection limit (MDL) calculated as per the USEPA method [24] based on 9 measurements $(n=9)$ of low concentration standards $(0.5-10 \mu \mathrm{g} / \mathrm{L}) . \mathrm{R}^{2}$ values are from calibration curves with intercept forced through zero. Bias was determined using untreated surface water, groundwater, and tap water ( $\mathrm{n}=3$ of each water type), all spiked with $20 \mu \mathrm{g} / \mathrm{L}$ of each analyte, and is expressed as the mean percentage of spiked recoveries over all samples. Relative standard uncertainties were calculated employing an uncertainty budget that incorporated precision of replicate spiked samples, calibration standard preparation, sample volume and linear regression of the calibration curve. All errors are reported as standard deviation. All quantification was via external calibration.

\begin{tabular}{|c|c|c|c|c|c|c|c|}
\hline \multirow{2}{*}{ Analyte } & \multirow{2}{*}{$\begin{array}{c}\mathbf{R}^{2} \\
(1-20 \mu \mathrm{g} / \mathrm{L})\end{array}$} & \multirow{2}{*}{$\begin{array}{c}R^{2} \\
(1-100 \mu g / L)\end{array}$} & \multirow{2}{*}{$\begin{array}{l}\text { MDL } \\
(\mu \mathrm{g} / \mathrm{L})\end{array}$} & \multicolumn{3}{|c|}{$\operatorname{Bias}(\%)$} & \multirow{2}{*}{$\begin{array}{c}\text { Standard } \\
\text { relative } \\
\text { uncertainty }(\%)\end{array}$} \\
\hline & & & & Tap Water & Source Water A & Source Water B & \\
\hline Bromochloronitromethane (BCNM) & 0.997 & 0.997 & 0.09 & $89 \pm 3$ & $110 \pm 10$ & $99 \pm 4$ & $11 \%$ \\
\hline Dichloronitromethane (DCNM) & 0.999 & 0.995 & 0.2 & $100 \pm 5$ & $110 \pm 15$ & $140 \pm 1$ & $7 \%$ \\
\hline $\begin{array}{l}\text { Bromodichloronitromethane } \\
\text { (BDCNM) }\end{array}$ & 0.958 & 0.982 & 1 & $45 \pm 3$ & $50 \pm 4$ & 0 & $8 \%$ \\
\hline $\begin{array}{l}\text { Dibromochloronitromethane } \\
\text { (DBCNM) }\end{array}$ & 0.915 & 0.967 & 2 & $27 \pm 5$ & $30 \pm 4$ & 0 & $29 \%$ \\
\hline $\begin{array}{l}\text { Tribromonitromethane (TBNM, } \\
\text { bromopicrin) }\end{array}$ & 0.873 & 0.928 & 6 & $13 \pm 4$ & $13 \pm 4$ & 0 & $26 \%$ \\
\hline $\begin{array}{l}\text { Trichloronitromethane (TCNM, } \\
\text { chloropicrin) }\end{array}$ & 0.998 & 0.993 & 0.08 & $93 \pm 2$ & $94 \pm 0.4$ & $87 \pm 5$ & $25 \%$ \\
\hline Bromoacetamide (BAAm) & 0.978 & 0.959 & 2 & $95 \pm 21$ & $160 \pm 28$ & $49 \pm 38$ & $34 \%$ \\
\hline Chloroacetamide (CAAm) & 0.974 & 0.977 & 1 & $99 \pm 9$ & $180 \pm 40$ & $98 \pm 19$ & $13 \%$ \\
\hline Dichloroacetamide (DCAAm) & 0.992 & 0.990 & 0.08 & $100 \pm 9$ & $160 \pm 4$ & $96 \pm 15$ & $6 \%$ \\
\hline Trichloroacetamide (TCAAm) & 0.996 & 0.996 & 0.1 & $97 \pm 4$ & $110 \pm 4$ & $94 \pm 3$ & $12 \%$ \\
\hline
\end{tabular}


Table 2. Concentrations of halonitromethanes (HNMs) and haloacetamides (HAAms) from select water treatment plants in Western Australia. Results from field blanks $(n=5)$ and trip blanks $(n=3)$ are not reported because they were all below detection. See Table 1 for definition of analyte acronyms.

\begin{tabular}{|c|c|c|c|c|c|c|c|c|c|c|c|}
\hline & \multicolumn{6}{|c|}{ HNMs $(\mu \mathrm{g} / \mathrm{L})$} & \multicolumn{5}{|c|}{ HAAms $(\mu \mathrm{g} / \mathrm{L})$} \\
\hline & BCNM & DCNM & BDCNM & DBCNM & TBNM & TCNM & BAAm & CAAm & DBAAm & DCAAm & TCAAm \\
\hline \multicolumn{12}{|c|}{ Groundwater WTP 1} \\
\hline Raw source water & $<0.09$ & $<0.2$ & $<1$ & $<2$ & $<6$ & $<0.08$ & $<2$ & $<1$ & $<0.1$ & $<0.08$ & $<0.1$ \\
\hline Post-Cl & $<0.09$ & 0.97 & $<1$ & $<2$ & $<6$ & $<0.08$ & $<2$ & $<1$ & 0.48 & 0.19 & $<0.1$ \\
\hline Reticulation & $<0.09$ & $<0.2$ & $<1$ & $<2$ & $<6$ & $<0.08$ & $<2$ & $<1$ & 0.37 & 0.08 & $<0.1$ \\
\hline \multicolumn{12}{|c|}{ Groundwater WTP 2} \\
\hline Raw source water & $<0.09$ & $<0.2$ & $<1$ & $<2$ & $<6$ & $<0.08$ & $<2$ & $<1$ & $<0.1$ & $<0.08$ & $<0.1$ \\
\hline Post-Cl & $<0.09$ & 0.41 & $<1$ & $<2$ & $<6$ & $<0.08$ & $<2$ & 9.2 & 0.86 & 0.21 & $<0.1$ \\
\hline Storage Reservoir & $<0.09$ & 0.83 & $<1$ & $<2$ & $<6$ & $<0.08$ & $<2$ & 7.6 & $<0.1$ & $<0.08$ & $<0.1$ \\
\hline Reticulation & $<0.09$ & 0.29 & $<1$ & $<2$ & $<6$ & $<0.08$ & $<2$ & $<1$ & $<0.1$ & $<0.08$ & $<0.1$ \\
\hline \multicolumn{12}{|l|}{ Surface WTP 3} \\
\hline Raw source water & $<0.09$ & $<0.2$ & $<1$ & $<2$ & $<6$ & $<0.08$ & $<2$ & $<1$ & $<0.1$ & $<0.08$ & $<0.1$ \\
\hline Post-Cl & $<0.09$ & $<0.2$ & $<1$ & $<2$ & $<6$ & $<0.08$ & $<2$ & $<1$ & 0.82 & 0.16 & $<0.1$ \\
\hline Reticulation & $<0.09$ & $<0.2$ & $<1$ & $<2$ & $<6$ & $<0.08$ & $<2$ & $<1$ & 1.7 & 0.58 & $<0.1$ \\
\hline
\end{tabular}



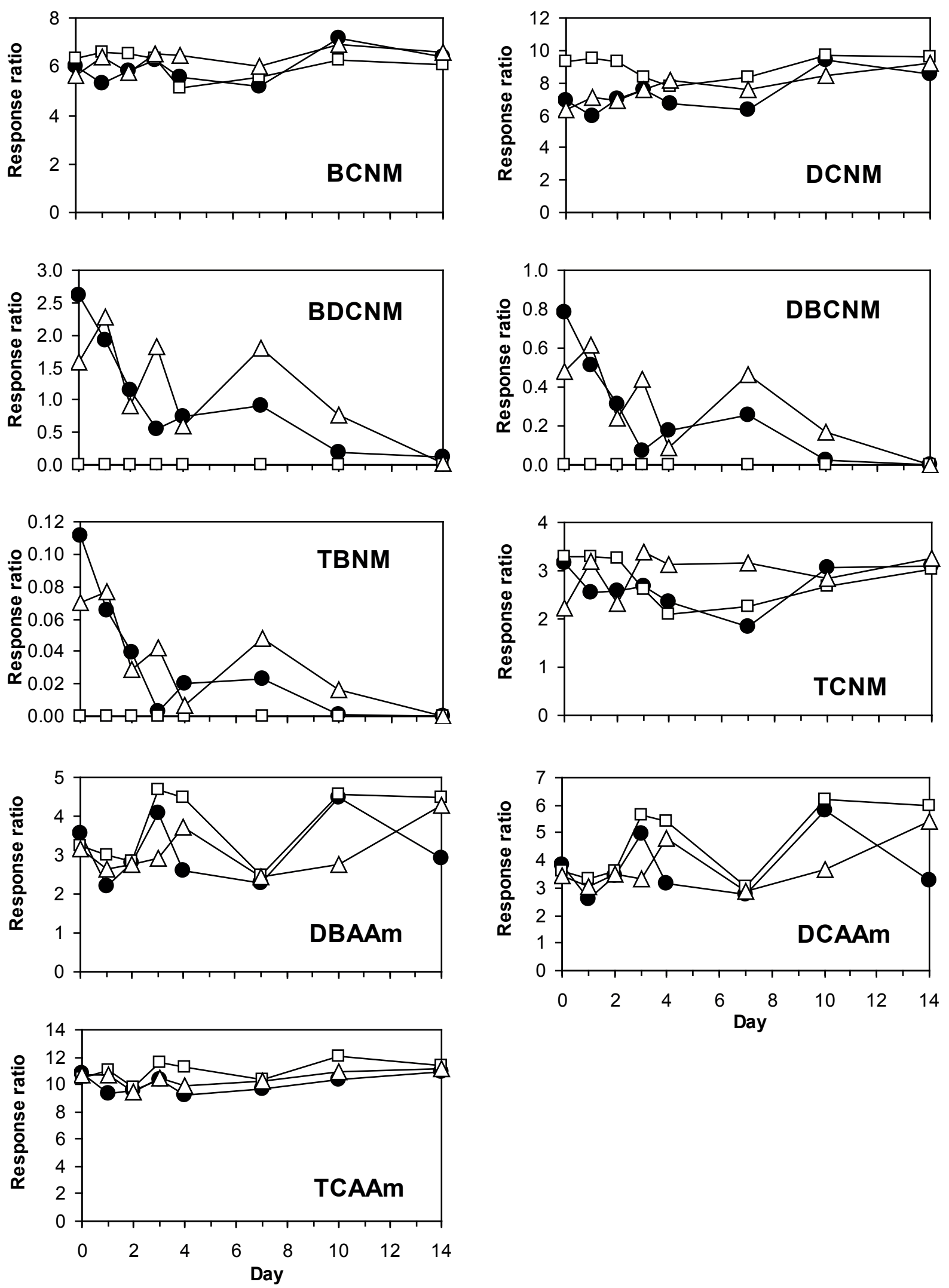

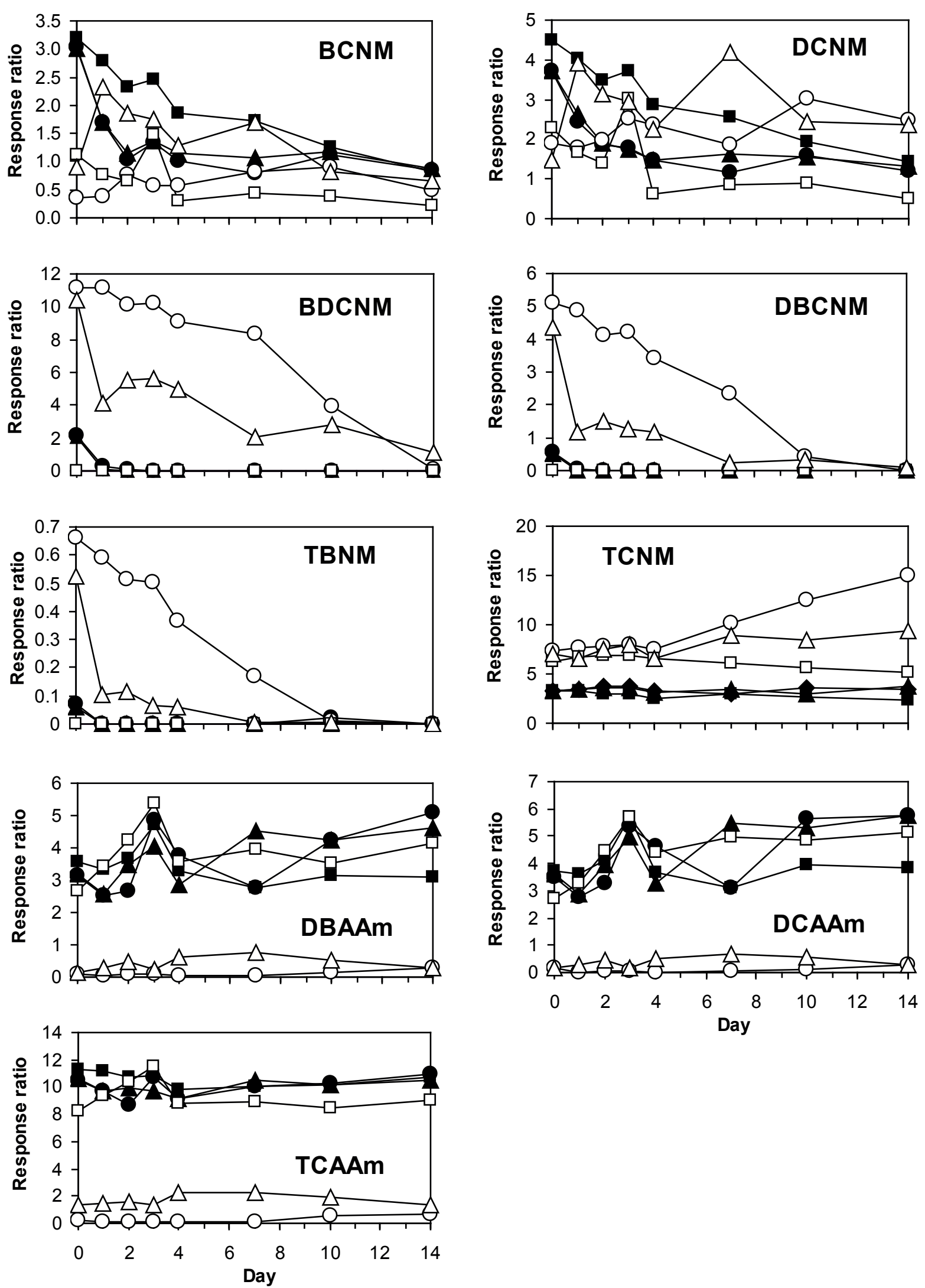